Article

\title{
Spatial Patterns of Vineyard Abandonment and Related Land Use Transitions in Beaujolais (France): A Multiscale Approach
}

\author{
Etienne Cossart ${ }^{1, * \mathbb{C}}$, Jessica Pic ${ }^{1}\left(\right.$, , Yoann Le Guen ${ }^{1}$ and Mathieu Fressard ${ }^{2}$ \\ 1 CNRS UMR 5600 (Environnement Ville Société), Université de Lyon (Jean Moulin, Lyon 3), F-69008 Lyon, \\ France; jessica.pic@univ-lyon3.fr (J.P.); yoann@leguen.ovh (Y.L.G.) \\ 2 CNRS UMR 5600 (Environnement Ville Société), Université de Lyon (Lumière, Lyon 2), F-69500 Bron, France; \\ mathieu.fressard@univ-lyon2.fr \\ * Correspondence: etienne.cossart@univ-lyon3.fr
}

Received: 7 May 2020; Accepted: 4 June 2020; Published: 9 June 2020

\begin{abstract}
While the resilience of French vineyards is currently threatened, this paper focuses on the Beaujolais terroir, where the disappearance of vineyards has been qualitatively observed by local stakeholders. A targeted survey was led at three complementary scales. First, we provide an overview of the evolution of agricultural landscapes and practices for the whole Beaujolais area since 1990 from national statistical databases. It shows that the vineyard extent reached a maximum during the 1990s and that significant bifurcation occurred in 2000. Second, we document land use evolution in relation to vineyard abandonment at a more local scale. Three case studies (lower Ardières, Marverand, Merloux) exemplify the main local settings, and the land uses are described over time from an analysis that employed multitemporal photo interpretation. The results quantified the decrease in the vineyard surface extent since 1999: approximately 30\% was lost in regular terroirs and 5\% was lost in high added-value terroirs. Third, at a fine scale, we explained the precise location of the abandoned parcels regarding the site characteristics (e.g., incoming solar radiation, slope gradient, terroir quality). The results showed differences in evolution patterns between southern and northern Beaujolais. In northern Beaujolais, winegrowers tended to abandon vine parcels that were considered of lower quality; while, in southern Beaujolais, the winegrowers tended to abandon vine parcels in relation to the difficulty of maintenance (remote and steep parcels were preferentially abandoned) or in relation to suburbanization (parcels close to built-up areas were preferentially abandoned).
\end{abstract}

Keywords: vineyard; abandonment; landscape; land use; Beaujolais

\section{Introduction}

In a context of rapidly urbanizing societies, farmland abandonment is widely observed and a specific need has emerged to survey concomitant agricultural land use changes. Some large scientific reviews and meta-analyses have recently been published on this topic in Europe, their results showing the prime importance of land abandonment among the wide range of trajectories of land use changes [1-3]. Land abandonment indeed affects large surface areas [4] and may impact agricultural productivity, landscape closure, or biodiversity [5]. Underlying drivers of agricultural abandonment are part of a complex combination of spatial processes that have hitherto not been fully described and understood $[3,6]$. Explanatory case studies are thus still required, especially with a focus on non-marginal areas [6]. These cases involve a wide range of complex drivers and there is a need to document the extent of abandoned land, the stages of abandonment, and the factors leading to the abandonment of particular plots [5]. 
French vineyards appear well-suited to reach this objective, especially in regions now facing a decrease in the spatial extent of vineyards, such as the Mediterranean areas and Beaujolais $[7,8]$. In the latter cases, some changes during the recent period (since the 1990s) have affected the resilience of vineyards. They were indeed affected by international economic competition (e.g., competition with South American, Australian, South African, and Spanish wines), followed by new consumer demands in terms of public health and well-being (e.g., organic growing and reduction of pesticides). In addition, environmental changes (e.g., soil erosion, urban pressure, and climate change) have profoundly modified the functioning of vineyards as socioeconomic systems [9-11].

Among the French vineyards, the Beaujolais area has not been studied, although its location is strategic for addressing two main issues regarding land abandonment: the return to the natural environment due to land abandonment [12] and the threat from suburbanization [8]. The Beaujolais area is indeed located close to the Lyon metropolitan area ( 2 million inhabitants) but also close to the deep rural areas to the west (population density lower than 20 inhabitants $/ \mathrm{km}^{2}$ ). This region can thus be influenced by some contradictory driving forces. Furthermore, Beaujolais exhibits many proxies of a collapse of the vineyard system: (i) reductions in the area devoted to vineyards [13], (ii) decreases in vineyard land prices ranging from 30\% to 70\% over a decade [14], and (iii) the fact that approximately one-third of the winegrowers are going to retire without any succession in the next decade [14]. As vineyards perform additional economic, environmental, and sociocultural functions in rural areas [15-17], stakeholders wonder how this may threaten the organization of the whole territory [9].

In this paper, we seek to document the spatial patterns of vineyard abandonment in Beaujolais and characterize the primary factors driving the abandonment. Spatial patterns were evaluated at three complementary scales to address three main issues. First, an overview of the evolution of agricultural landscapes and practices at the regional scale is provided for the whole Beaujolais area since 1990. The objective at this scale was to decipher the abandonment patterns linked, on the one hand, to the suburbanization of the Lyon conurbation and, on the other hand, the spread of natural vegetation. Second, we documented the land use evolution related to vineyard abandonment at a more local scale in three areas (lower Ardières, Marverand, Merloux) that exemplify the main local settings. We coupled an examination of aerial photographs acquired at three dates $(2017,2007,1999)$ with field investigations (observation of vegetation cover, interview of stakeholders) to draw diachronic maps. The objective was to highlight the main transitions (i.e., type and rate of land use conversion) that occurred at the plot scale for the last two decades. Third, at a fine scale, we explain the precise location of abandoned parcels regarding the site characteristics (e.g., incoming solar radiation, slope gradient, terroir quality). Collectively, these data seek to provide a typology of the processes resulting in the abandonment of vineyards and quantify the concomitant impacts on the landscape.

\section{Study Area}

\subsection{Physical Settings and Land Use}

Located in the lower part of the Saône catchment, in the northern part of the Rhône department, the Beaujolais wine region is approximately fifty kilometers long from the northern Lyon conurbation to the southern Mâcon (Figure 1). The vineyards are more precisely located along the eastern hillslopes of the Massif Central and are bounded further east by the alluvial plain of the Saône River. Regarding the climate, the annual precipitation is approximately $850 \mathrm{~mm}$ and is regularly distributed throughout the year. The area receives approximately $1900 \mathrm{~h}$ of solar radiation per year, and hot temperatures exceeding $30^{\circ} \mathrm{C}$ are quite typical during summer [18]. 


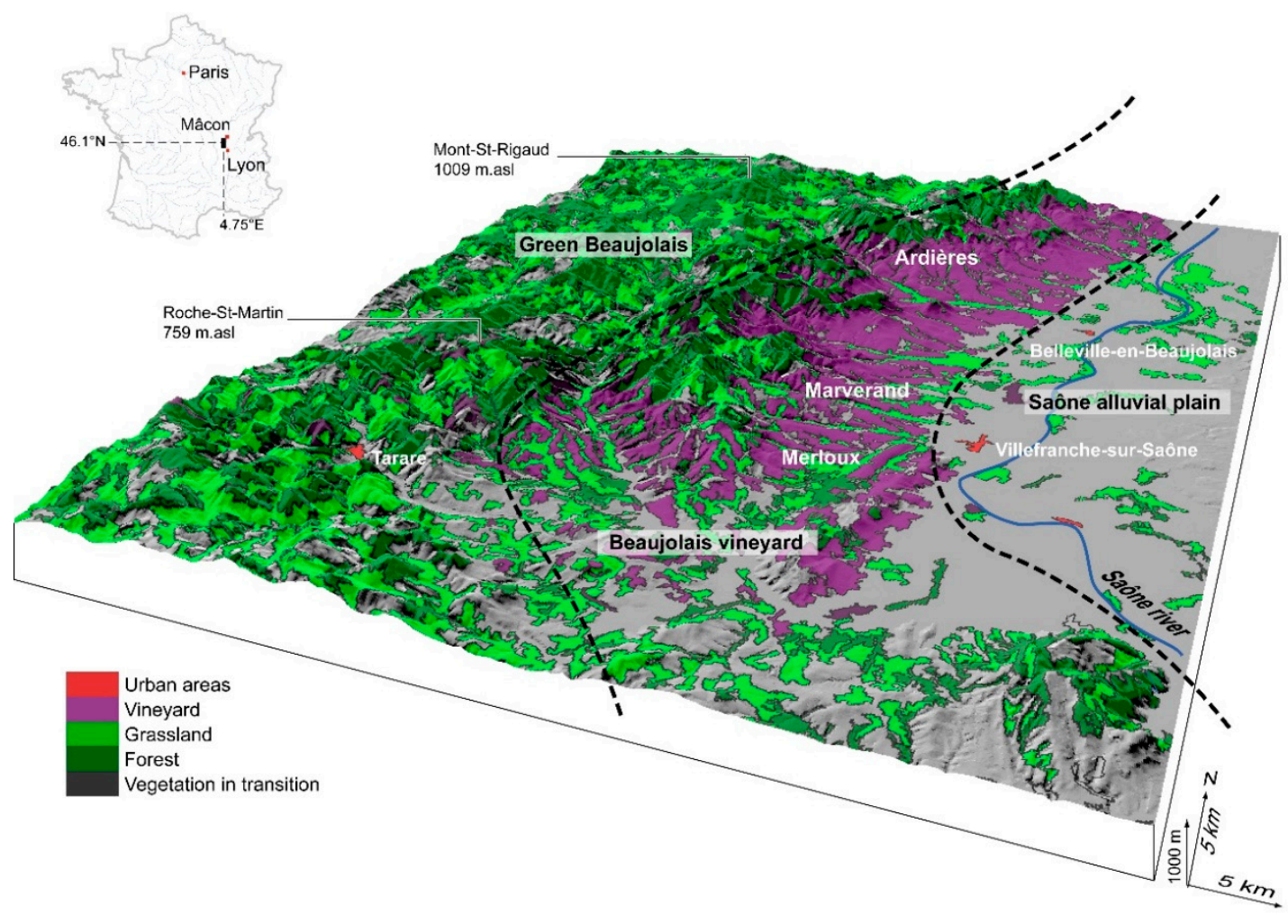

Figure 1. Location of Beaujolais and land use within the study area. Source: Corine land cover (2017) and IGN (National Institute of Geographic and Forestry Information).

At the regional scale, the Beaujolais landscape can be subdivided into three main components (Figure 1).

(1) The western part of Beaujolais (named "green Beaujolais") corresponds to the highest altitudes (summits can reach 800 to $900 \mathrm{~m}$.asl) and is characterized by a mixed landscape that alternates between forested areas (logging) and grasslands (extensive grazing). Only a few towns and isolated farms are located in this subregion, where inhabitant density is low (ranging from 10 to 100 inhabitants $/ \mathrm{km}^{2}$ ). Defined as a deep rural area, this subregion is considered affected by a general trend of economic and agricultural decrease [14,15].

(2) To the east, the altitudes decrease towards the alluvial plain of the Saône River (approximately 170 m.asl). Below 450 to 500 m.asl, wine growing is a dominant activity, especially on hillslopes.

(3) Grazing meadows, cereal crops, and vegetable farms were observed in the valley bottoms and in the Saône alluvial plain [14]. This area encompasses the two main cities of Beaujolais: Villefranche-sur-Saône (37,000 inhabitants) and Belleville-en-Beaujolais (8000 inhabitants). These two cities provide jobs related to administrative and commercial activities, as well as transport services that provide easy access to Lyon and Mâcon. As a consequence, the processes of urban sprawl from Villefranche-sur-Saône and Belleville-en-Beaujolais can be qualitatively observed, but these processes have been only infrequently documented.

\subsection{Diversity of Beaujolais Appellations}

The Beaujolais vineyard encompasses three main types of appellations (Figure 2), which are well differentiated in the hierarchy of wine classifications. 


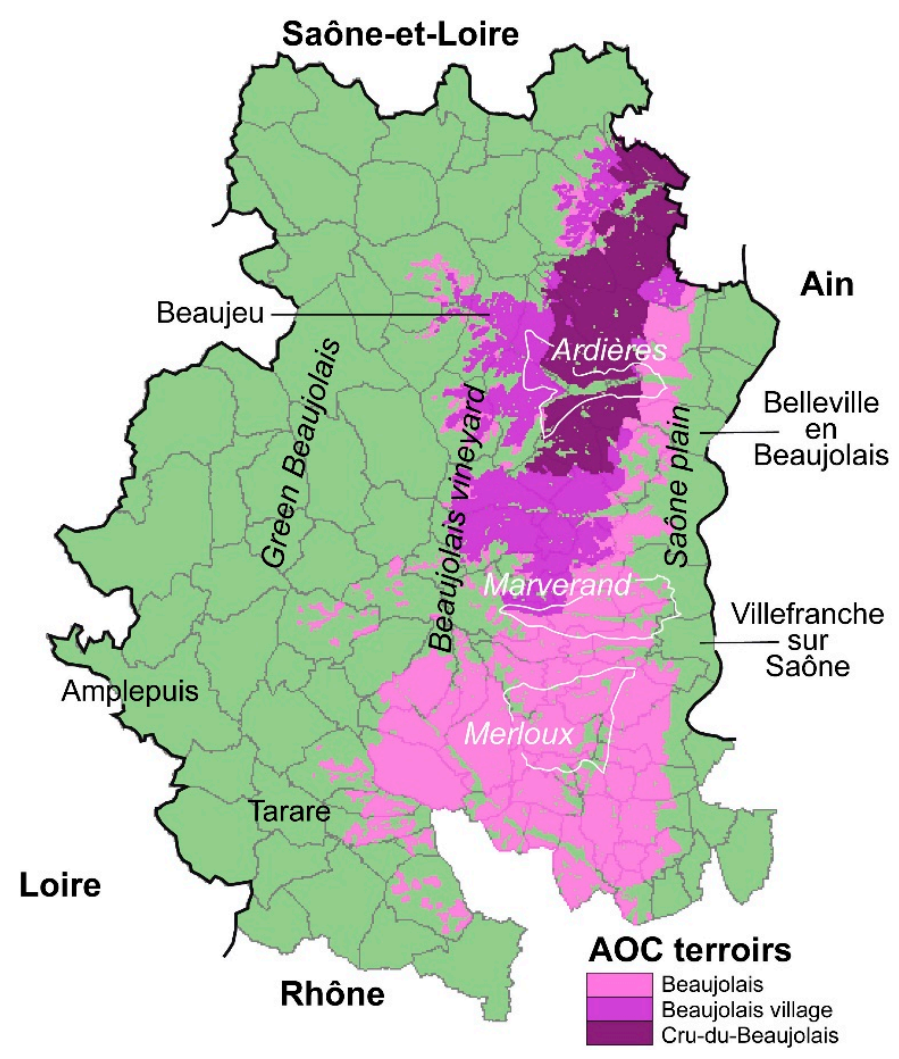

Figure 2. Location of Institut National des Appellations d'Origine (INAO) classified AOC terroirs. Source: Agreste, French Ministry of Agriculture.

The regular and regional wine appellation is "AOC (Appellation d'Origine Contrôlée) Beaujolais". The wines are mainly produced south of Villefranche-sur-Saône and to a lesser extent in the northern part of Beaujolais, along the Saône River. The main characteristic of this appellation is related to the soils developed over calcareous rocks or alluvial regoliths. The name of the appellation may be supplemented by the words "new" or "early", which corresponds to the wines authorized for early selling. Generally, these wines are considered lower quality than those mentioned below.

A second regional appellation is "AOC Beaujolais-village", which corresponds to the wines produced in the delimited territory of the 38 communes north of Villefranche-sur-Saône. Wine from the "village" terroir is considered to be of intermediate quality.

The third type of appellation is the "AOC Cru-du-Beaujolais", which is made of 10 local vintages (Brouilly, Côte de Brouilly, Morgon, Régnié, Fleurie, Chiroubles, Chénas, Juliénas, Saint-Amour, and Moulin-à-Vent). These vintages are considered the best quality and are located on the best terroirs: steep slope vineyards with southern and southeastern aspects. The main distinction between the terroirs relies on the geology, which can be made of granite, schist, or other resistant metamorphic or volcanic rocks (diorite, tuf).

The distinction between a vintage and a regular AOC is important in terms of wine prices and vineyard plot prices. Vintage wine bottles are sold at higher prices but are also considered by consumers to be of higher quality, which means that wine growers may be less affected by international economic competition. This trend can be exemplified by the price per hectare of wine plots. From 2011 to 2018, the average prices ranged from $€ 91,000$ per hectare for land producing vintage Moulin-à-Vent (northern AOC Cru-du-Beaujolais) to $€ 11,000$ in a simple Beaujolais appellation (southern AOC Beaujolais) [14].

\subsection{Brief History of Beaujolais Vineyards}

The Beaujolais wine economic system has been experiencing an economic crisis for over 20 years, especially because of a controversial reputation. Since the mid-20th century, "Beaujolais nouveau" 
(i.e., early Beaujolais) is considered of moderate quality and is sold during celebrations at the end of November. It is sold very soon after grape harvesting. While this celebration of an early and quick macerated wine has ensured the reputation and wide diffusion of Beaujolais nouveau during the 1980s and 1990s, current changes in consumer demand tend to reduce its economic opportunities. Such celebrations are counterproductive in terms of marketing, as wine consumers now prefer wines of better quality in terms of taste but also in terms of wine-growing practices (reduced pesticide use, increased adoption of organic practices). In this context, Beaujolais vineyards furthermore cope with two external drivers that act at a more regional scale (Figure 3). On the one hand, the demographic growth of the Lyon metropolitan area has generated urban sprawl since the 2000s, especially along the Saône River and around secondary cities (e.g., Amplepuis and Tarare). On the other hand, the green Beaujolais area is subject to general abandonment (population and economic decrease) that in some areas results in natural vegetation spreading and a consequent increase in forested surface areas. Combined with international economic competition (especially with Spain, South America, South Africa, and Australia), these driving factors have led to a current crisis conveyed through (i) a decrease in production of nearly one-third between 2000 and 2012 [14] and (ii) a reduction of approximately $20 \%$ (4400 hectares) in the vineyard surface area (Figure 3 ).

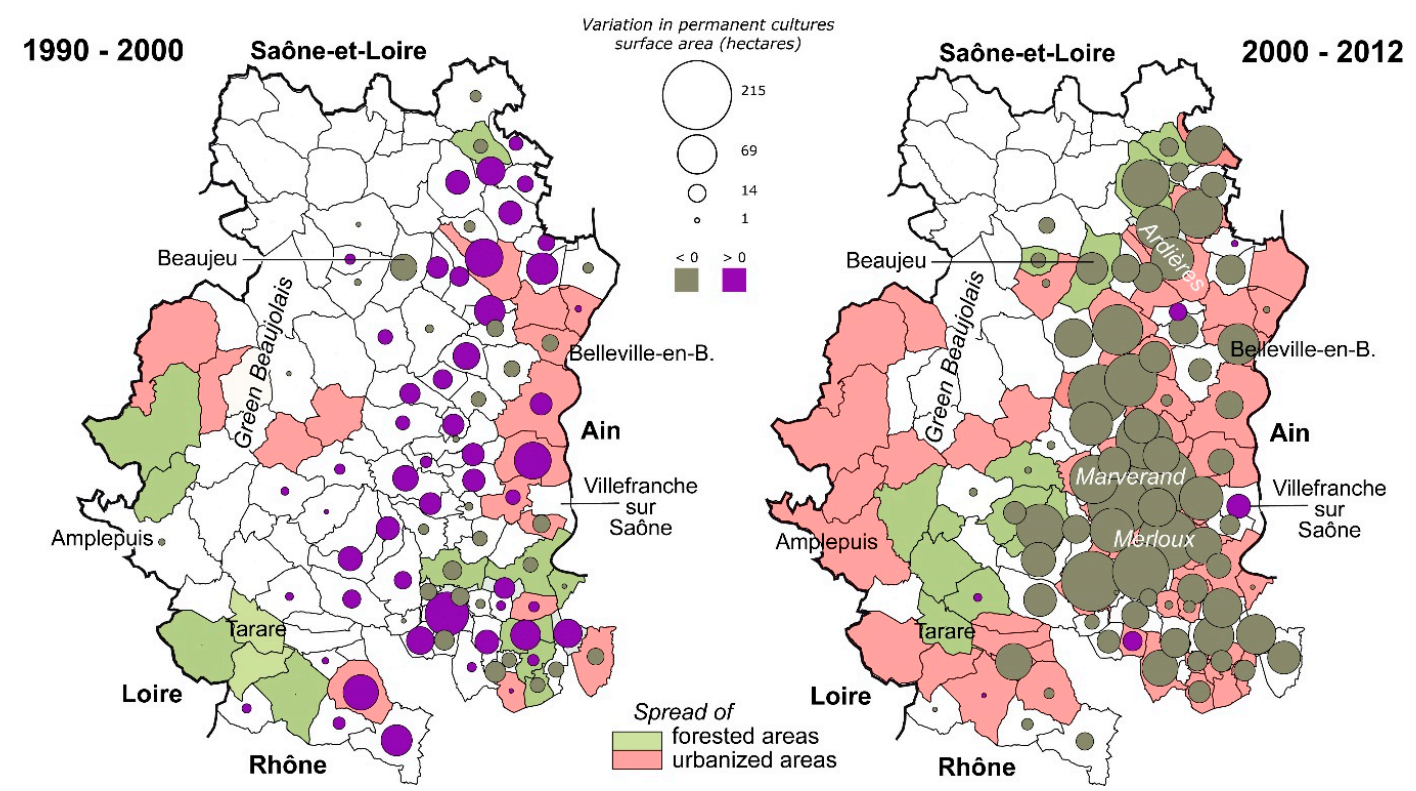

Figure 3. Evolution of the main types of land uses in Beaujolais since 1990. Source: French Institute for Statistics and Economical Studies (INSEE).

The impact of vineyard abandonment on the landscape can be observed even if it has not been hitherto quantified. The concomitant expansion of forest and urban areas is among the most frequent modifications perceived by stakeholders and observed in the field (Figure 4). These trends had to be confirmed through an exhaustive survey, particularly because abandoned parcels of vineyards may have variable vegetation characteristics in Beaujolais (Figure 4). Many abandoned parcels were indeed affected by a complete removal of vineyards, making them very similar to grassland after abandonment (Figure 4). To conserve biodiversity of open habitats that are threatened by shrub encroachment and landscape closure [19], the European Union and the Rhône Department offered financial incentives to owners who agreed to remove vineyards between 2000 and 2010. It also encouraged the reduction in annual production and rebalanced the prices of Beaujolais wine. 

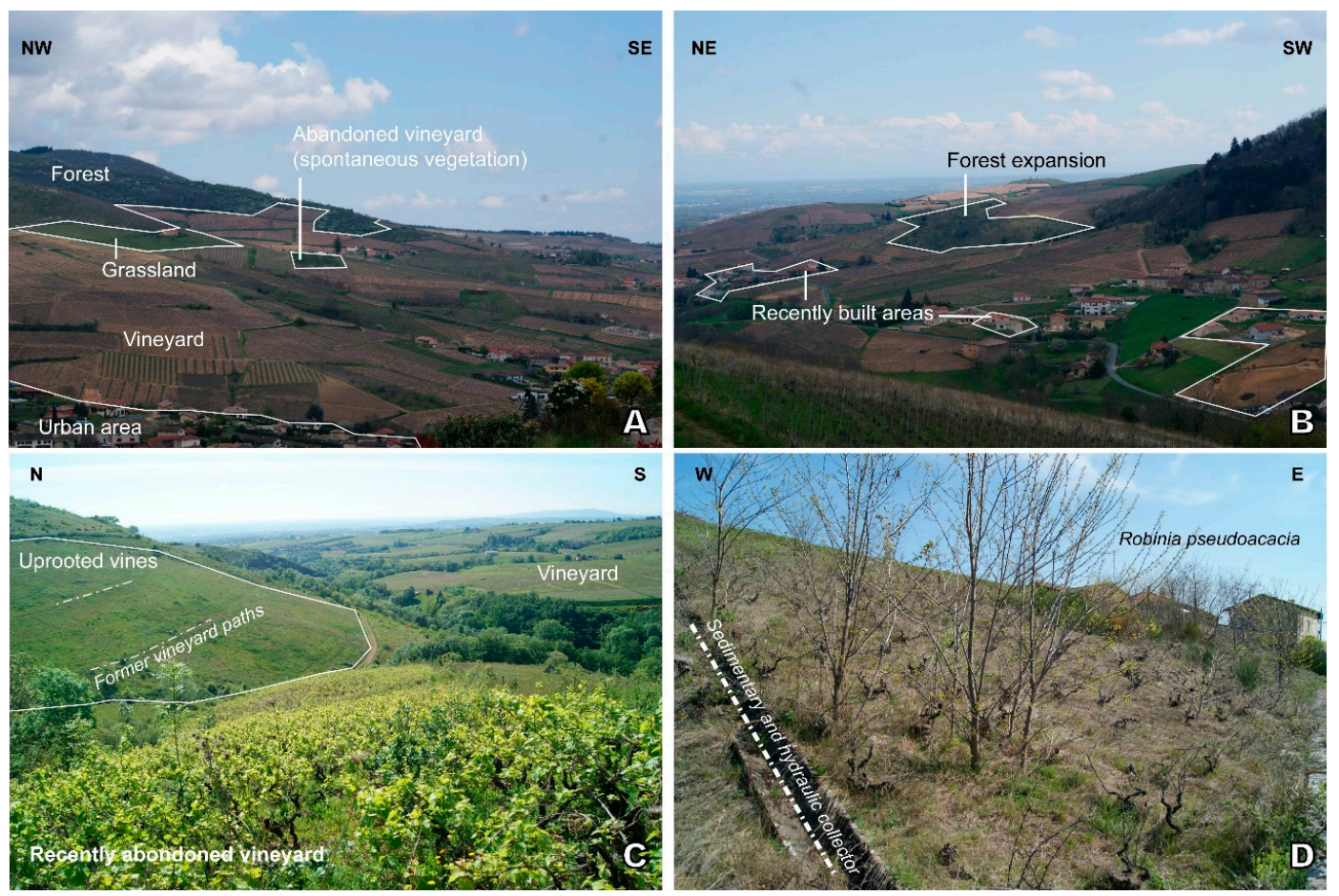

Figure 4. Landscapes associated with the main land uses in Beaujolais. (A): Typical vineyard landscape (Chiroubles, Ardières catchment, April 2019); (B): Symptoms of degradation of the vineyard (urban sprawl, expansion of forest; Chiroubles, Ardières catchment, April 2019); (C): Examples of recently abandoned vine parcels in which the vines were not uprooted are shown in the foreground, while in the field on the left, the vines were uprooted (Blacé, Marverand catchment, May 2019); (D): Abandoned vine plot where trees (Robinia pseudoacacia) are growing; the abandonment occurred approximately 15 years ago (Villié-Morgon, Ardières catchment, April 2019). Source: photographs by Yoann Le Guen and Jessica Pic.

\section{Methods}

\subsection{Spatiotemporal Survey at the Regional Scale}

At the regional scale, we sought to show the relationship between vineyard evolution and two external drivers: suburbanization (urban sprawl from the Lyon metropolitan area) and agricultural decrease in deep rural areas (landscape closure from green Beaujolais). In that way, we considered the whole Beaujolais area, the spatial extent of which corresponds to Figure 2. A temporal database was built from INSEE (French Institute for Statistics and Economical Studies) data to reveal the geographical assemblage (sensu Anderson and McFarlane [20]) of Beaujolais. For each municipality (127), we selected for three dates $(1990,2000,2012)$ variables focusing on agricultural activities (surface of all cultivated areas, proportion of grassland, proportion of vineyard/orchards, proportion of market gardening/cereals, breeding activity, number of farmers) and on the landscape structure (area of forests, area of urbanized and artificial areas, area of wetlands).

From this database, a spatiotemporal principal component analysis (PCA) was conducted to identify how all variables were cross-correlated and thus to reveal the main driving factors that coevolved with vineyards. The features involved in the PCA corresponded to the municipalities at each date, so 381 features were considered within the calculation procedures and represented on the final biplot. The features were then aggregated at the municipality scale to exhibit the trajectory of each municipality between 1990 and 2010 on the biplot. To help the interpretation, a hierarchical clustering analysis (Euclidian distance, wards-linkage method) was also applied to the PCA results to provide an objective typology of municipalities and to facilitate synthetic mapping. All procedures were conducted using the Factominer package in R software [21]. 


\subsection{Land Use Conversion at the Study Site Scale}

\subsubsection{Three Case Studies}

Considering the locations of the appellations within Beaujolais, we specifically focused on three sites: (i) the Ardières area in the north, where the vintage "Cru-du-Beaujolais", "AOC Beaujolais-village", and "AOC Beaujolais" appellations are located; (ii) Marverand, where the AOC Beaujolais-village and AOC Beaujolais appellations are located; and (iii) Merloux in the south, where only the regular AOC Beaujolais terroirs are located. The three study areas were of comparable surface area and had similar altitudinal ranges (170 m.asl to 600-700 m.asl) and aspect (east-southeast).

The selected area called the "lower Ardières" corresponds to the lower part of the Ardières catchment (downstream of Beaujeu). It covers an area of $44 \mathrm{~km}^{2}$ (from 170 to $588 \mathrm{~m}$.asl) and is characterized by a mean slope gradient of $8.5 \%$ (maximal value $=62 \%$ ). Marverand, which is located to the south of the lower Ardières, is a catchment with a surface area of approximately $46 \mathrm{~km}^{2}$ (from 167 to $732 \mathrm{~m}$.asl) and a mean slope gradient of $7.3 \%$ (maximal value $=100 \%$ ). Merloux is a catchment of approximately $32 \mathrm{~km}^{2}$, with altitudes ranging from 193 to $652 \mathrm{~m}$.asl. The mean slope gradient is higher: $14 \%$ (maximal value $=67 \%$ ).

\subsubsection{Database Acquisition}

We sought to reconstruct the evolution of land use in the three selected areas (lower Ardières, Marverand, Merloux) since the end of the 1990s, i.e., the beginning of the economic crisis and the concomitant process of vineyard abandonment. The main objective was to document the main land use transition patterns that have occurred during the last two decades: individual plots were characterized over time. Open source databases, such as Corine land cover, quickly seemed useless because of a coarse resolution that hampers the identification of land use types. Corine land cover can be useful for parcels of more than 25 hectares; however, the majority of the parcels in Beaujolais have surface areas ranging between 0.1 and 0.5 ha.

After an inventory of all available data characterized by a sufficiently high resolution, we selected aerial photographs acquired from three periods: 1999, 2007, and 2017. They all corresponded to high-resolution photographs where the vegetation was clearly visible and identifiable; there were no clouds and the photographs were taken during spring (exacerbating the differences between forests, grasslands, shrubs, and vineyards). The high-resolution orthophotograph database (BD-Ortho HR ${ }^{\circledR}$ ) of the IGN was used for the 2017 land use characterization. Among the images available in 2007, the satellite images provided by Google Earth Pro software were of the highest quality (especially in terms of resolution). The aerial photographs from 1999 (IGN) were selected as they fit the three main selection criteria: (1) acquired at the beginning of the economic crisis, (2) acquired in spring, and (3) sufficient resolution (i.e., 1/25 000). For this year, the raw aerial photographs from the IGN were orthorectified based on a set of ground control points manually acquired from the 2017 image and a Digital Elevation Model (DEM).

To facilitate the comparison of land uses over time, we considered the cadastral plots available from the IGN (BD Parcellaire ${ }^{\circledR}$ ) since they had a constant geometry since 2000. Furthermore, a cadastral plot is the operational scale at which management actions and operations are decided through owner prioritization, making it a suitable scale to discuss the abandonment pattern. Each cadaster parcel was manually photointerpreted on each date, and this method still remains the most accurate technique for generating such maps as it limits the uncertainty [22]. The main land use of each parcel was identified and entered into the database using Quantum GIS software ${ }^{\circledR}$. The land use nomenclature we applied included eight types: buildings (B), crops other than vines (C), zones of extraction of materials $(\mathrm{EM})$, abandoned areas $(\mathrm{W})$, forests and woodlands areas $(\mathrm{F})$, grasslands $(\mathrm{G})$, hydrological areas $(\mathrm{H})$, and vines $(\mathrm{V})$. Each land use type was characterized through field surveys, with a specific focus on ensuring the identification of abandoned areas (Figure 4C,D), which are difficult to identify through classic methods of remote sensing [23-25]. We specifically noted whether 
the former infrastructure typical of vine plots was still visible even if the grapes had been removed. For instance, former paths and ditches demonstrate the former cultivation of vines. Semistructured interviews (eight respondents) with selected key stakeholders (local farmers and decision makers) also provided qualitative information. Respondents specifically had to confirm whether some plots were truly abandoned or not. More generally, they helped in the description of how people use the land, and then to interpret land use changes and not only land cover changes [26,27]. They also helped in the interpretation of all the underlying driving forces of landscape change and the impacts of agricultural policies on the livelihood of farmers and farm management.

\subsubsection{Analysis Through Transition Graphs}

Using the spatiotemporal database, our objective was to assess the type and frequency of transitions related to vineyard abandonment. The evolution of spatial entities over time generates transitions that can be assimilated into spatiotemporal networks [26,27]. These networks summarize the main transitions that have occurred: they exhibit both the type of transitions and the frequency of each possible transition [28,29]. Modeling of a phenomenon as a network (i.e., graph) requires identifying the entities (nodes or vertices) and the relationships (links edges) that link them in space and time. The nodes corresponded to a parcel on one date, and the links corresponded to the type of transition occurring between a parcel on one date and the same parcel on a later date. From this exhaustive graph, which is difficult to read, we constructed a synthetic graph. The nodes were then the main types of land use patterns (types of nomenclature), and the links corresponded to the land use change patterns that were observed.

\subsection{Statistical Analysis at the Parcel Scale}

To define the set of rules or processes that governed vineyard abandonment, we tested the roles of some spatial properties of the settings of the abandoned parcels. First, the spatial context was considered to reflect the interactions between abandoned parcels and the nearby environments $[8,30]$. Second, the local characteristics of the parcels (e.g., topography) also corresponded to explanatory variables [31]; the influence of these variables was assessed to ascertain the extent to which some spatial patterns, in particular, led to the abandonment of vine growing.

\subsubsection{Plot Adjacency Analysis}

The spatial context for a polygon as a parcel was here defined as the set of neighboring polygons, which are polygons that share a common edge [32]. In the present case, we thus created an adjacency matrix (an edge list) through a GIS procedure. By applying the "shared polygon edges" tool (C SAGA GIS 7.1.1), we provide an inventory of all types of existing borders. We also included Moore neighbors, i.e., polygons that shared a single common point (queen contiguity rule), in our dataset. From the edge list, a graph summarizing the adjacency patterns between the main types of land use was created through R software (i-graph package) [21]. These graphs were drawn from 2017 land use maps to exhibit the kinds of spatial contexts that favored the presence of abandoned vineyard parcels. In detail, we counted the number of adjacency links $\left(\mathrm{N}_{\mathrm{AK}}\right)$ that were observed between the abandoned parcels (category notation A) and parcels of each possible type of land use (generic notation K). To interpret the $\mathrm{N}_{\mathrm{AK}}$ values, we compared the count with the expected theoretical value, which was calculated as follows:

$$
\mathrm{N}^{\prime}{ }_{\mathrm{Ak}}=\mathrm{N}_{\mathrm{A}} \cdot\left(\mathrm{N}_{\cdot \mathrm{k}} / \mathrm{N} . .\right)
$$

where $\mathrm{N}_{\mathrm{Ak}}$ is the expected number of adjacency links between an abandoned parcel (A) and a parcel of any type of land use (called $\mathrm{K}$ ), $\mathrm{N}_{\mathrm{A}}$. is the total number of adjacency links involving abandoned parcels (whatever the type of neighboring polygon), $\mathrm{N}_{. \mathrm{k}}$ is the total number of adjacency links involving parcels of category K (whatever the type of neighboring polygon), N.. is the total number of adjacency links within the study area. The underlying assumption was that a random distribution of adjacency 
links involving abandoned parcels (A) would be organized proportionally to the number of adjacency possibilities provided by each type (K) of parcel. Finally, if $\mathrm{N}_{\mathrm{AK}}>\mathrm{N}_{\mathrm{Ak}}^{\prime}$, then the observed adjacency links between the abandoned parcels and the parcels belonging to category $\mathrm{K}$ were higher than expected, meaning that a spatial context including a category $\mathrm{K}$ parcel should favor the abandonment of a parcel. Conversely, if $\mathrm{N}_{\mathrm{AK}}<\mathrm{N}_{\mathrm{Ak}}^{\prime}$, then the observed adjacency links between the abandoned parcels and parcels belonging to category $\mathrm{K}$ would be lower than expected, meaning that a spatial context including a category $\mathrm{K}$ parcel should hinder the abandonment of a parcel.

\subsubsection{Local Physical Characteristics of the Plots}

To complement the role of the spatial context, three other datasets were considered to characterize the parcels: slope angle, incoming solar radiation, and AOC type. Slope gradient and incoming solar radiation are classical topographic factors that influence terroir quality; therefore, they may have influenced the choice of parcels where abandonment occurred. We hypothesize that the higher the quality of the terroir (i.e., higher slope gradient, high incoming solar radiation, AOC vintages), the lower the probability of abandonment. In the same way, the AOC type to which a parcel belonged was supposed to directly influence the price of the parcels and then the probability of abandonment.

The AOC vector map (Figure 2) was acquired from the INAO (Institut National des Appellations d'Origine) spatial data, which is available on Geoportail (IGN). The slope gradient and incoming solar radiation maps were derived from the French national digital elevation model (BDAlti ${ }^{\circledR}$ ) using the libraries of SAGA GIS 7.1.1.

Multiple logistic regression has been applied to explain efficiently (dis)appearance of vineyards [6]. This method was performed between the response variable (abandonment/maintenance of vineyards) and four explanatory variables (slope gradient, incoming solar radiation, distance to build-up areas, AOC type). The regression was implemented through $\mathrm{R}$ [21]; odds ratios, z-value, and p-value were calculated to assess the strength and significance of the correlations.

\section{Results}

\subsection{Coevolution of Vineyards, Suburbanization, and Landscape Closures at the Regional Scale}

The spatiotemporal database acquired at the regional scale was summarized through the PCA technique. The first two principal components (PC) gathered almost $70 \%$ of the total information (Figure 5). In detail, the first PC (PC1) gathered $45 \%$ of the information and primarily revealed the level of agricultural intensity. Both variables that revealed agricultural activity (surface area dedicated to agriculture, number of farmers) were inversely proportional to the scores on PC1. It can be observed that the highest levels of agricultural intensity were correlated with vine growth. In contrast, the lowest levels of agricultural activity (high scores on PC1) were associated with breeding activities but also with the surface area covered by forests and other natural environments. The second PC (PC2) was mostly associated with the surface dedicated to market gardening and with the surface area corresponding to urban areas. Both variables mostly revealed a suburbanized setting. The surface area covered by wetlands was also associated with PC2, suggesting that municipalities characterized by high values of PC2 tended to be located along rivers and on valley floors.

The Hierarchical Clustering Analysis (HCA) procedure exhibited three main clusters of municipalities (Figure 5) that mostly fit with the three main subregions of Beaujolais (Figure 6): the Saône plain (class 1), green Beaujolais (class 2), and Beaujolais vineyard (class 3). Class 1 grouped all municipalities characterized by high scores on PC2, and it can be considered a group of suburbanized municipalities, which were mostly located along the Saône River and close to the Lyon metropolitan area. Class 2 grouped municipalities with moderate and low scores on PC2 but with high scores on PC1. It thus corresponded to the municipalities with low levels of agricultural activities but also scarce surface areas of urbanized areas. These municipalities were clustered in the west (green Beaujolais). Finally, the class 3 municipalities were mostly characterized by the lowest (negative) scores on PC1, 
which was associated with high levels of agricultural activity and large surface areas of vineyard and orchard areas.
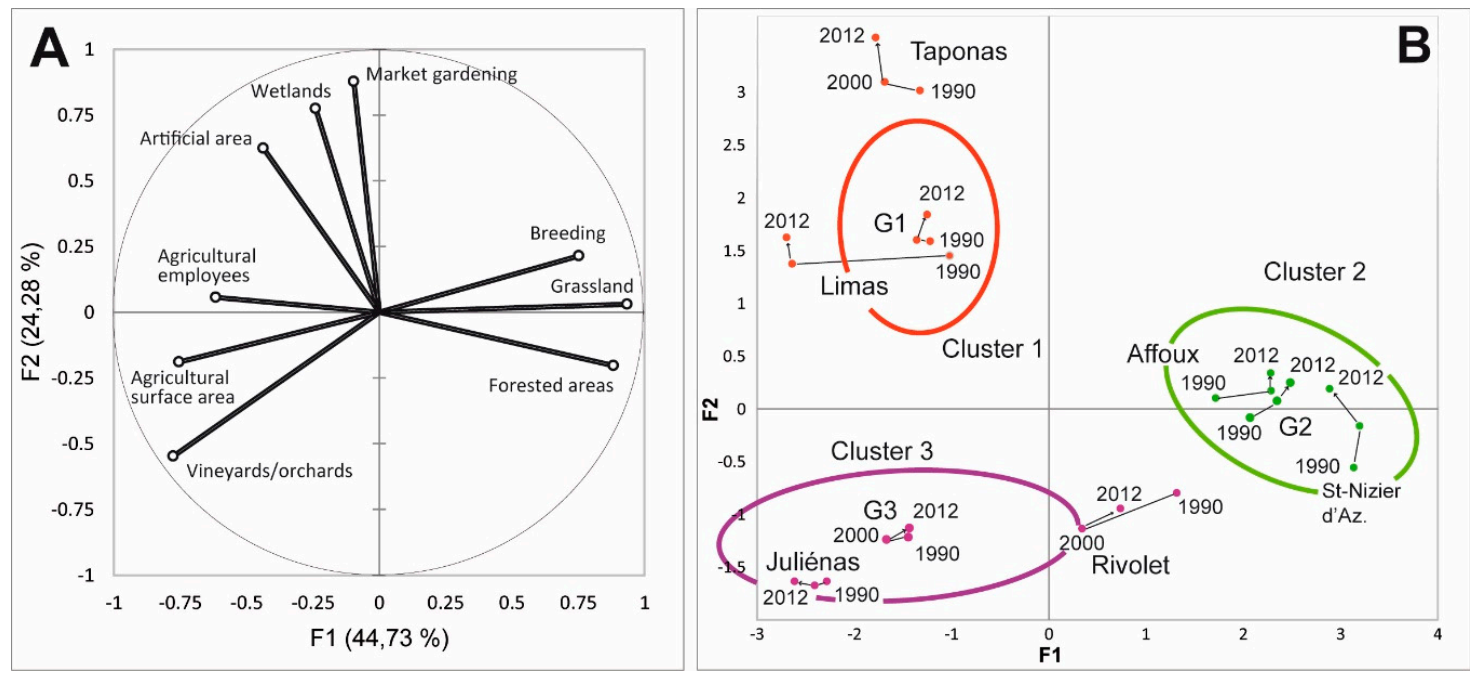

Figure 5. Results of the spatiotemporal principal component analysis (PCA). (A). Biplot of variables; (B). Biplot representing some selected municipalities and their evolution between 1990 and 2012. Selected municipalities are representative of the main trajectories.

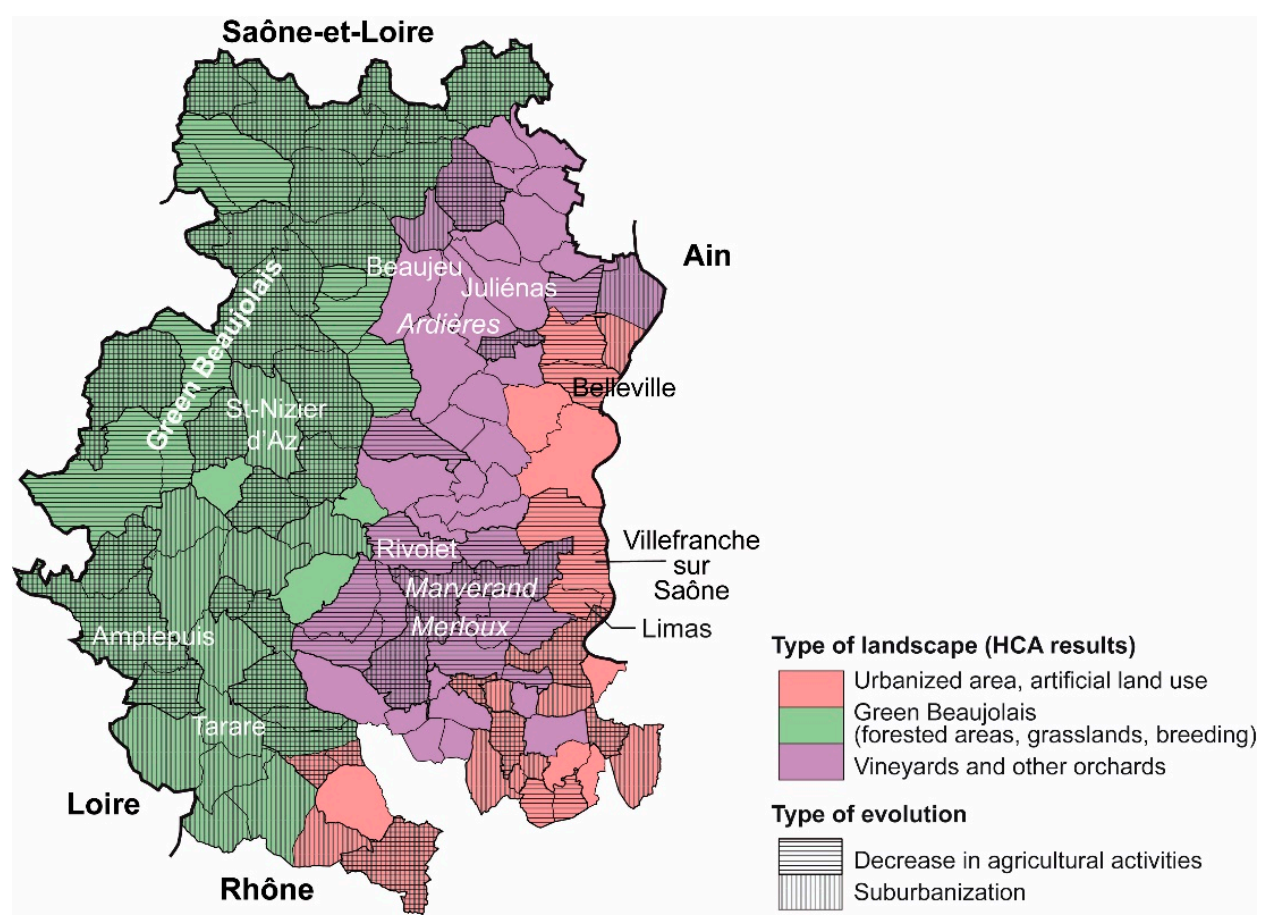

Figure 6. Main evolution of land uses and agricultural activities in Beaujolais since 1990. Results of the PCA and HCA.

Some changes were observed within each class between 1990 and 2012. In class 1, the main observed trend corresponded to urban sprawl from Lyon and the main cities (i.e., Villefranche-sur-Saône and Belleville-en-Beaujolais). This trend was summarized by the shifting coordinates of the center of gravity of the class and can be exemplified by the cases of Taponas and Limas. In class 2, the evolutions were subdued but mostly corresponded to an elevation of PC2 scores. The evolution of the coordinates of the center of gravity exhibited two trends: a decrease in the agricultural activity and a slight increase in the wooded/forest surfaces. More specifically, it may have corresponded to an increase 
in the surfaces dedicated to urbanized areas (e.g., St-Nizier-d'Azergues), but more generally, it was associated with market gardening sprawl (e.g., Affoux). The trends observed in class 3 revealed a significant bifurcation during the considered period. The coordinates of the center of gravity exhibited a decrease in the PC1 scores between 1990 and 2000, which was followed by an increase between 2000 and 2012, revealing that the crisis affected the vineyard in 2000. More particularly, two main types of municipality evolution were observed. On the one hand, in most cases, the pattern revealed by the center of gravity was exacerbated, and the elevation of PC1 scores since 2000 was significant (e.g., case of Rivolet, Figure 5). These municipalities were mostly observed in the southern part of the region (Figure 6). On the other hand, some municipalities did not exhibit elevation of PC1 scores since 2000 (e.g., Juliénas), suggesting that the surface areas dedicated to vineyards, and more generally the level of agricultural activity, have not decreased. These municipalities were clustered in the area where the AOC Cru-du-Beaujolais appellations are located (Figure 6).

The results showed two main spatial trends in terms of the evolution at the regional scale. The main result was that suburbanization processes were confirmed and affected a wide area (Figure 6). Even if they mostly occurred in the eastern and southern parts of the region, they also occurred locally in green Beaujolais. A decrease in agricultural activity was also exhibited and mostly affected deep rural areas in green Beaujolais. Both trends may affect the vineyard to various extents. The northern part seemed to be more stable (e.g., lower Ardières area), so the hypothesis of a better resilience of high-quality vineyard terroirs was reinforced. In the southern part, some areas were threatened by both processes (e.g., Marverand area), while others were only affected by the decrease in agricultural activity (e.g., Merloux area).

\subsection{Landscape Evolution at the Study Site Scale}

\subsubsection{Lower Ardières}

In the lower Ardières area in 1999 (Figure 7), the main land use corresponded to the vineyard, with vine crops accounting for $58 \%$ of the total surface area. Grasslands $(17 \%)$, urban areas $(12 \%)$, other crops $(7 \%)$, and wooded areas (5\%) corresponded to the other main land uses. Although a few parcels of spontaneous vegetation were observed locally in the northernmost part of the watershed, they represented less than $0.5 \%$ of the total surface area. In 2007 , the main spatial patterns of land use remained mostly unchanged, while between 2007 and 2017, some parcels of vineyards were abandoned (vines corresponded to $56 \%$ of the total surface area in 2017). The transition graph of the lower Ardières (see below) confirmed that 108 hectares of vines disappeared during the last two decades.

Vineyard disappearance was of the cause of $57 \%$ of all observed transitions. The associated types of transition were as follows: abandoned vine crops becoming grassland $(34 \%$ of all inventoried transitions), vines becoming abandoned areas (14\%), and vines becoming urban areas (9\%). Consequently, one main trend corresponded to the emergence of abandoned areas: almost absent in $1999(<0.5 \%)$, they represented 36 ha in $2017(1 \%)$. More surprisingly, we noticed that a significant proportion of the grasslands were converted into urban areas. While the grassland surface area appeared stable during the considered period, the transition graph highlighted that it reached a dynamic equilibrium, i.e., a balance between the gain from vineyards and the loss to urban areas. Therefore, there was an indirect trend towards urban sprawl from the vineyard. In detail, the transformation process may have occurred in many stages, i.e., by an initial transformation of the vineyard into grasslands. The transition graph also shows that no significant transition occurred from the abandoned parcels. Such land use appears to have been permanent and stable at the timescale of this study. 


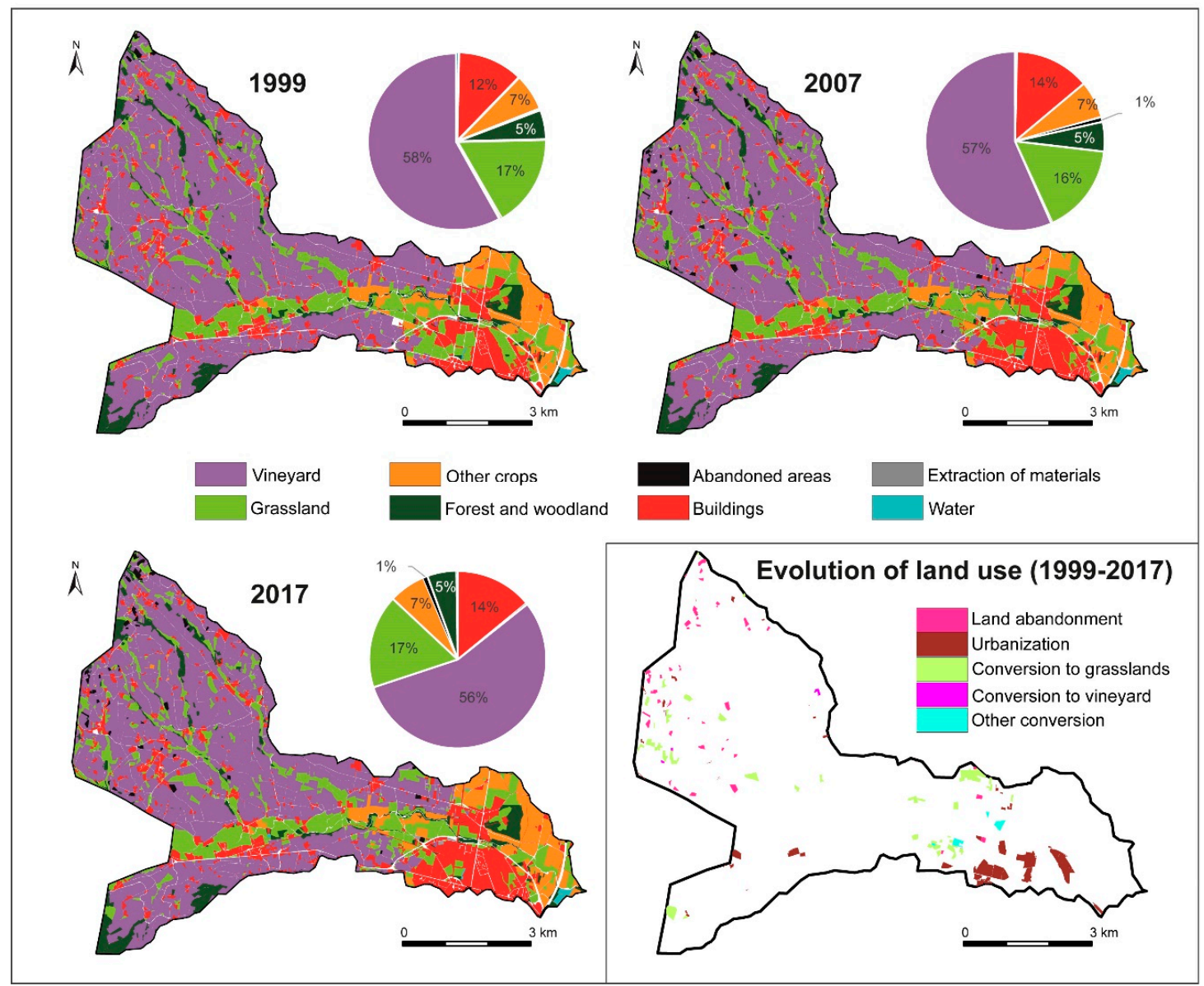

Figure 7. Evolution of land uses in lower Ardières between 1999 and 2017.

\subsubsection{Marverand}

In the Marverand catchment in 1999 (Figure 8), vineyards were the main observed type of land use: they represented $36 \%$ of the total surface area. The other land use types were grassland $(25 \%)$, urban areas $(14 \%)$, other crops $(13 \%)$, and forests $(11 \%)$. As in lower Ardières, no parcel of abandoned area was observed during the study period. Nevertheless, the vineyard surface area decreased between 1999 and 2007 (vines corresponding to 32\% of surface area in 2007), a trend that was exacerbated between 2007 and 2017 (shifting from 32 to $25 \%$ ).

The transition graph of the Marverand catchment (see below) showed that the disappearance of the vineyards was responsible for $77 \%$ of all the observed transition patterns. Most of the vine crops became grassland (50\% of all changes) and abandoned areas ( $25 \%$ of all changes). As a consequence, vineyards were not the main type of land use; they only represented $25 \%$ of the total surface area. Concomitantly, grasslands became the main land use (29\% of the surface area), while $3 \%$ of the catchment was converted into abandoned area. Grasslands appear as transitional land use types within complex landscape transformations, leading to permanent land uses (e.g., urban area and forest).

\subsubsection{Merloux}

In the third case study, most of the surface area corresponded to vineyard in 1999 (Figure 9): 44\% of the total surface area was occupied by vine crops, while grassland occupied $22 \%$, forests $18 \%$, and urban areas $13 \%$. As in the two other study cases, no abandoned parcel was observed at that time. The evolution of land use (1999-2017) was characterized by a significant decrease in the vineyard surface extent: approximately one-third has been replaced by grasslands and abandoned areas. As observed in Marverand, such trends were significantly reinforced between 2007 and 2017. 


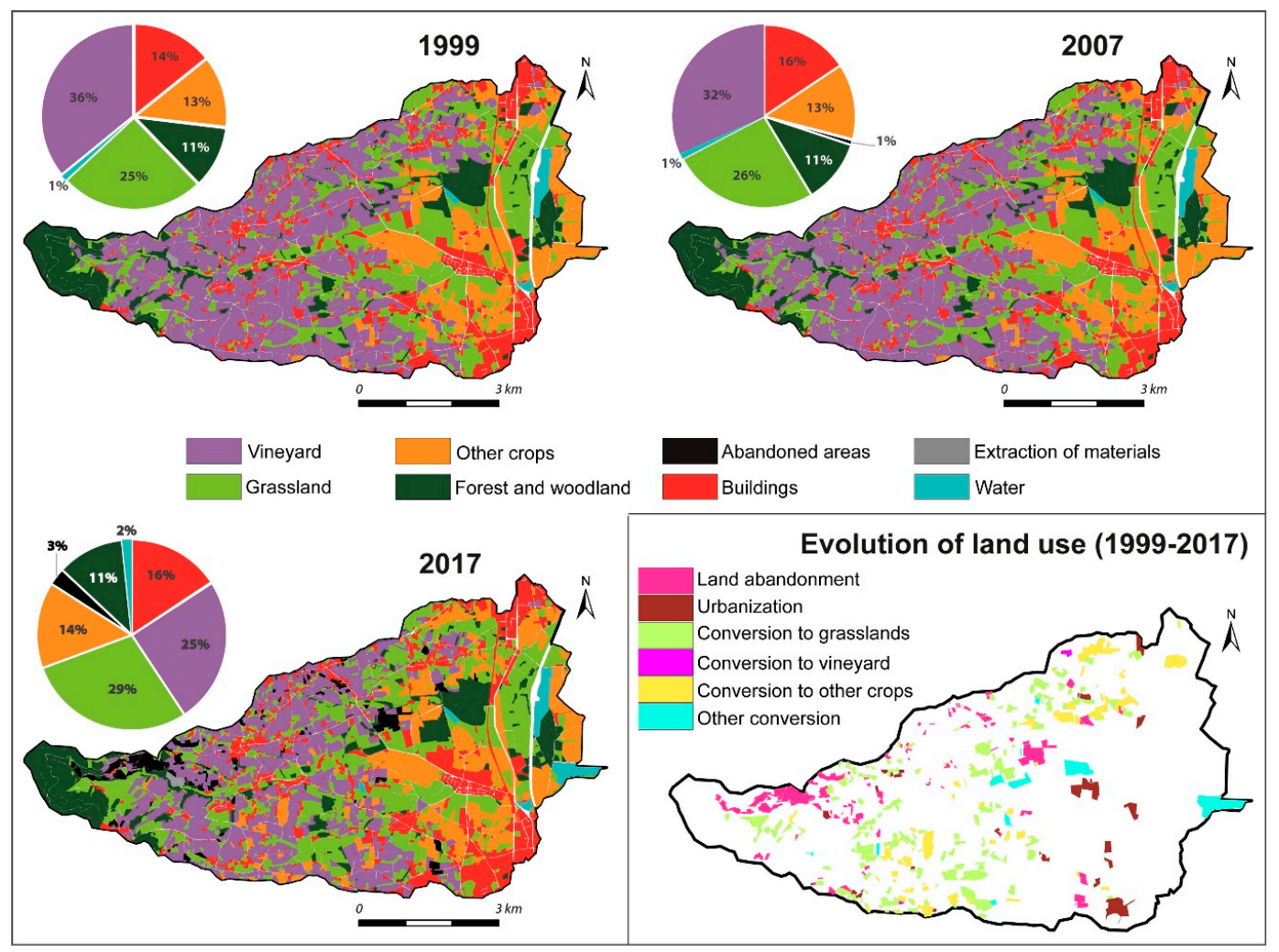

Figure 8. Evolution of land uses in Marverand between 1999 and 2017.

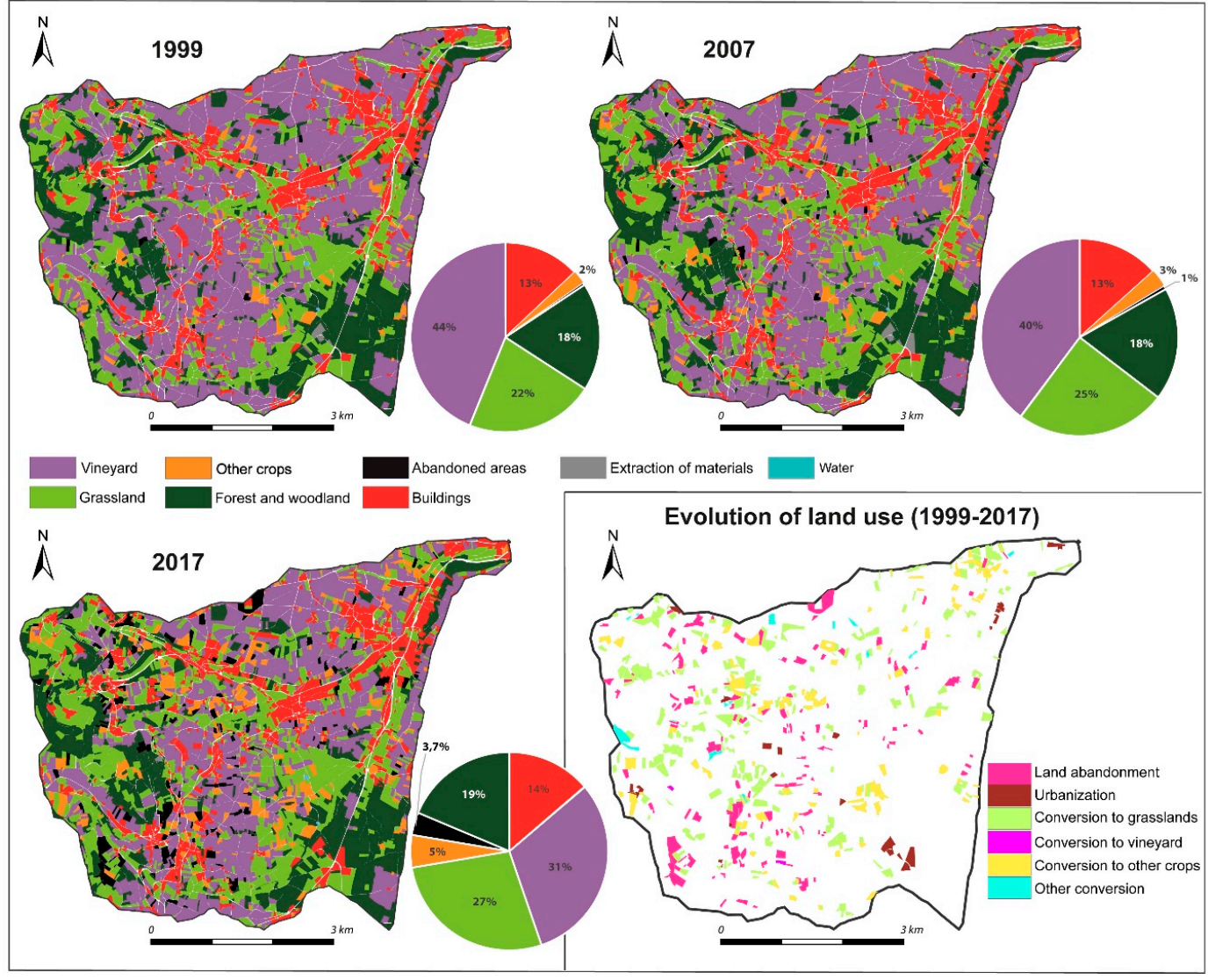

Figure 9. Evolution of land uses in Merloux between 1999 and 2017. 
Finally, vine crops only occupied $31 \%$ of the total surface area during the final study period, and the transition processes from vineyards represent $89 \%$ of all transition patterns (Figure 10). These decreases in vineyard surface area provided space for the conversion of crops to grassland, abandoned areas, and other crops ( $48 \%, 26 \%$, and $24 \%$ of all changes, respectively). Therefore, the surface area occupied by grasslands become of primary importance ( $28 \%$ of the total surface area) and almost equaled the surface area of vineyards. We noticed that the grassland surface area reached a dynamic equilibrium: grassland can be considered a temporary land use during the process of transition between vineyards and other land uses (in the study area, market gardening areas, or abandoned areas). Abandoned areas corresponded to $4 \%$ of the total surface area in 2017.

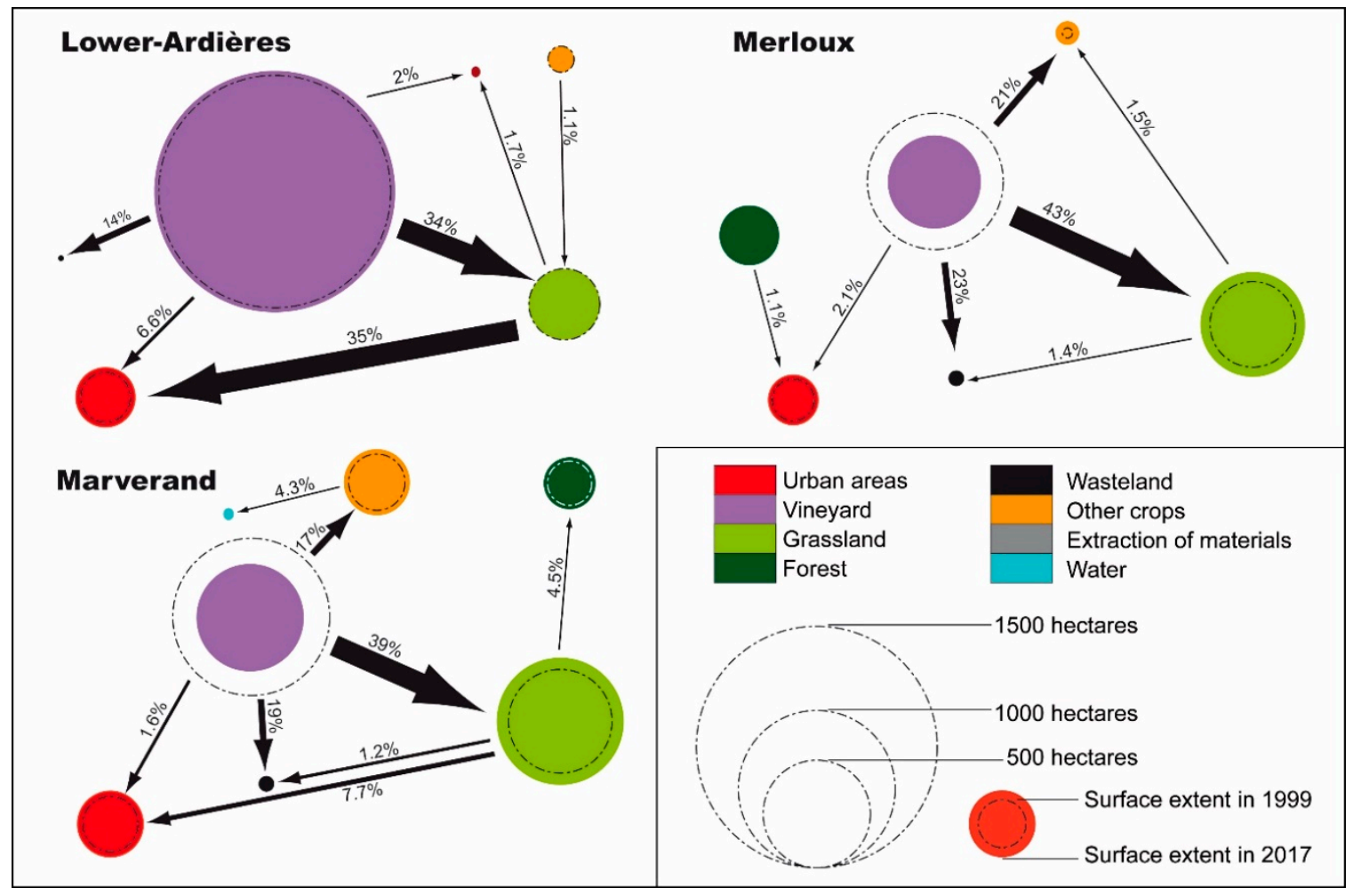

Figure 10. Transition graphs synthetizing the spatiotemporal patterns of land use evolution from 1999 to 2017 at the three study sites.

\subsection{Driving Forces Behind Vineyard Abandonment at the Local Scale}

\subsubsection{Influence of the Spatial Setting}

The spatial pattern of the parcel abandonment differed between lower Ardières on the one hand and Marverand and Merloux on the other. Indeed, in lower Ardières, the abandoned parcels appeared to be scattered throughout the vineyard areas (Figure 11). They were mainly located next to vineyard plots and did not show any spatial clusters. Indeed, they had few common edges.

In contrast, in both Marverand and Merloux, the abandoned plots were mainly located in direct proximity to urban areas and forest areas. Therefore, there was a bimodal distribution, so abandonment took place both in the direct vicinity of the areas affected by urban sprawl and in the areas characterized by remoteness. Moreover, the occurrence of abandoned lands was observed in the poorly accessible areas of the upper catchments (Figures 8 and 9). Furthermore, abandoned plots tended to be concentrated: they shared many boundaries with each other, resulting in large observable aggregates in the landscape. 
lower Ardières

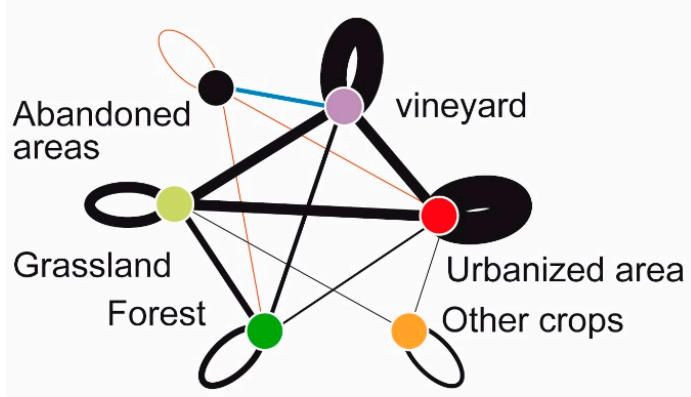

Number of shared edges

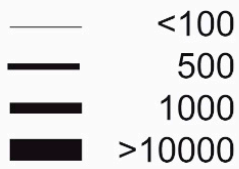

Adjacency to abandoned parcels - Frequency lower than expected Frequency higher than expected
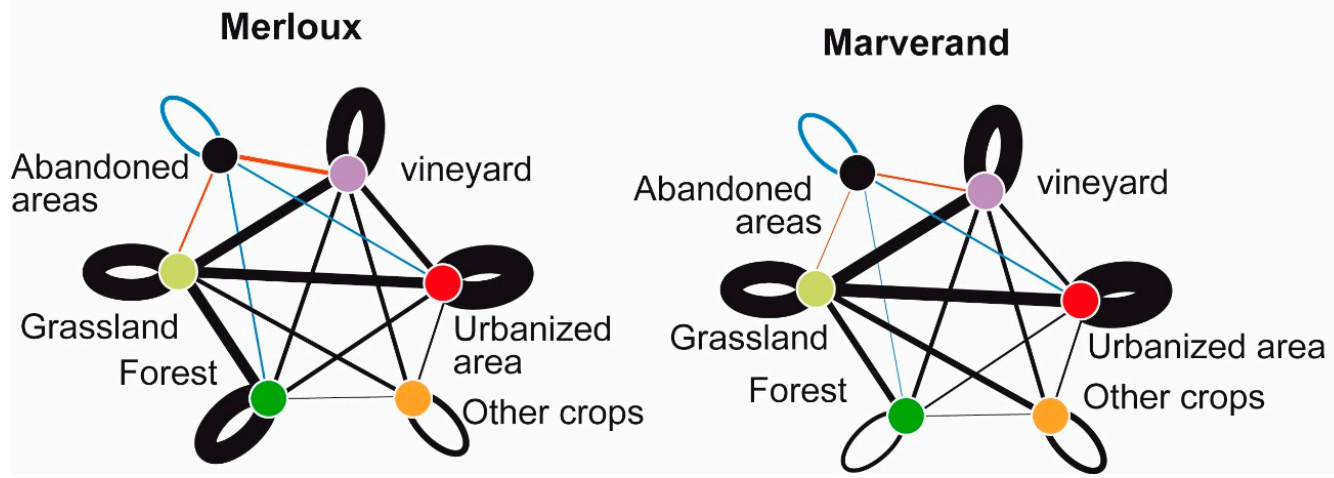

Figure 11. Graphs emphasizing adjacency patterns between abandoned parcels and the main land use types.

\subsubsection{Influence of Site Characteristics}

We tested the hypothesis that the higher the quality of the terroir was, the lower the probability of abandonment. This hypothesis was confirmed in lower Ardières, where appellation type had a strong influence on the location of the abandoned parcels of vines in the lower Ardières area (Figure 12 and Table 1). The abandoned vineyards were negatively associated with AOC vintages (i.e., Cru-du-Beaujolais, $\mathrm{OR}=0.06,95 \% \mathrm{CI} 0.04-0.10$ ), and to a lesser extent to Beaujolais-village appellation $(\mathrm{OR}=0.18,95 \% \mathrm{CI} 0.11-0.31)$. In other words, the probability to abandon a parcel of vineyard is significantly lower if it belongs to Cru-du-Beaujolais AOC and to Beaujolais-village AOC. Conversely, the most frequently abandoned vineyard parcels corresponded to the regular Beaujolais appellation. The role of other explanatory variables at the local scale was less significant. On the one hand, in the lower Ardières, descriptive statistics exhibit that abandoned vine plots were characterized by lower slope gradients (mean slope gradient $4.9^{\circ}$ ), while the vineyards were maintained on hillslopes (mean slope gradient $5.8^{\circ}$ ), which are considered terroirs of better quality (Figure 12). On the other hand, this result was contradicted by the logistic regression. Slope gradient was positively associated with vineyard abandonment ( $\mathrm{OR}=1.09 ; 95 \% \mathrm{CI} 1.04-1.14)$ : all things being equal, the probability of abandonment was higher on steeper hillslopes. We argue that this apparent contradiction is due to the fact that the steeper hillslopes mostly correspond to the best terroirs (Cru-du-Beaujolais and Beaujolais-village). The box plot of the lower Ardières catchment showed that abandoned vineyards were preferentially located on shaded hillslopes (Figure 12), i.e., that is considered of poor quality for vine growing. The statistical relationship between the incoming solar radiation and abandonment of vineyards is nevertheless not significant $(\mathrm{OR}=0.94 ; 95 \%$ CI $0.87-1.01)$.

The spatial patterns of vineyard abandonment were somewhat different in Marverand. The main common point was that abandonment of vine parcels was negatively associated with Beaujolais-village AOC (OR $=0.5,95 \%$ CI 0.42-0.59), so that abandonment appeared more frequent in the lower quality AOC plots (Beaujolais AOC). However, the mean slope angles of the abandoned vine parcels were slightly higher $\left(4.9^{\circ}\right)$ than those of the maintained vineyards $\left(4.3^{\circ}\right)$, a positive correlation that appears 
significant $(\mathrm{OR}=1.09,95 \% \mathrm{CI} 1.06-1.11)$. Remote areas were mostly affected by vineyard abandonment; the probability to abandon a parcel is positively associated with the distance to built-up areas (Table 1). Conversely, the box plots created for the Marverand area show that there was no specific trend between the abandonment of vines and the incoming solar radiation on parcels (Figure 12), a fact that was confirmed by the logistic regression (OR $=1.01,95 \%$ CI $0.98-1.04)$. Collectively, the spatial patterns revealed that parcels considered difficult to work were given priority for abandonment.

The Merloux area also exhibited preferential abandonment of steeper vineyards (OR $=1.14$, 95\% CI 1.12-1.16). The abandoned vineyards were located on parcels where the slope gradient was approximately $8.5^{\circ}$, while the slope gradient was approximately $6.2^{\circ}$ on the parcels where the vineyards were maintained. In this case study, the distance to built-up areas is also significant (Table 1): parcels close to built-up areas were primarily affected by abandonment. In a context in which there are only terroirs of lower quality, and in which the proximity to Lyon metropolitan area is at its highest, this result may be related to suburbanization processes.

A

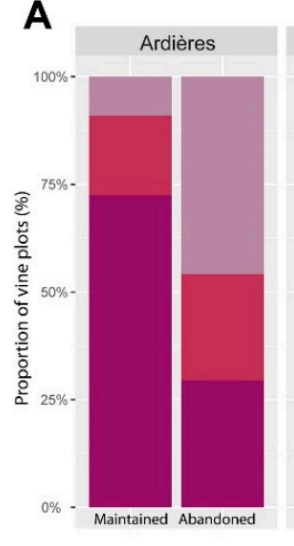

B

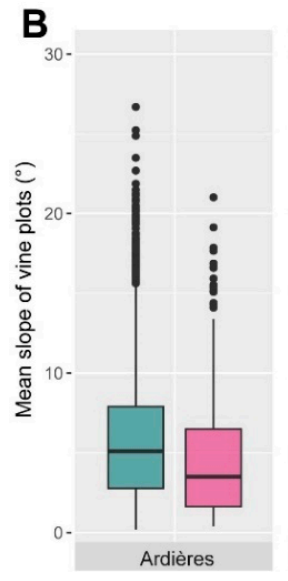

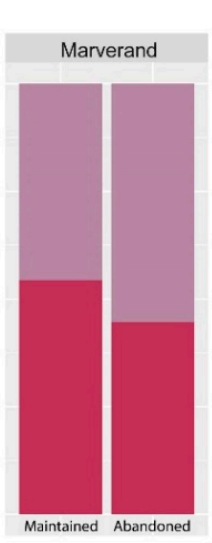
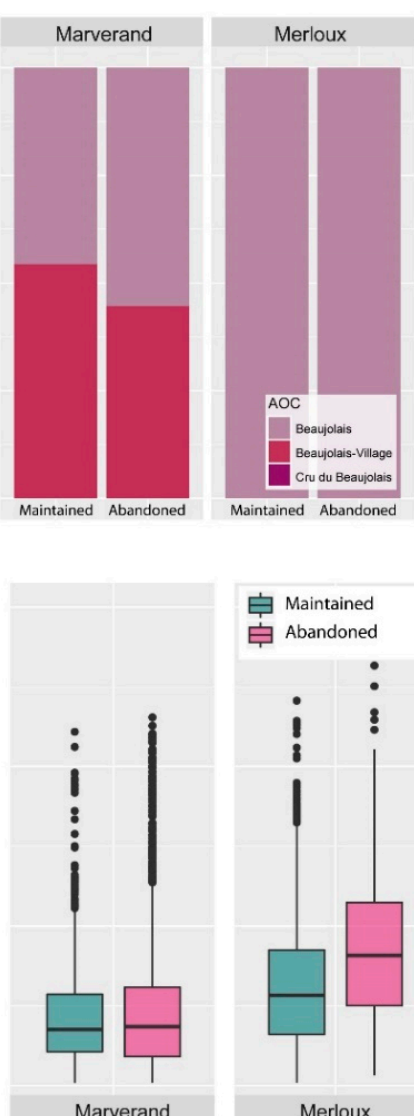

C

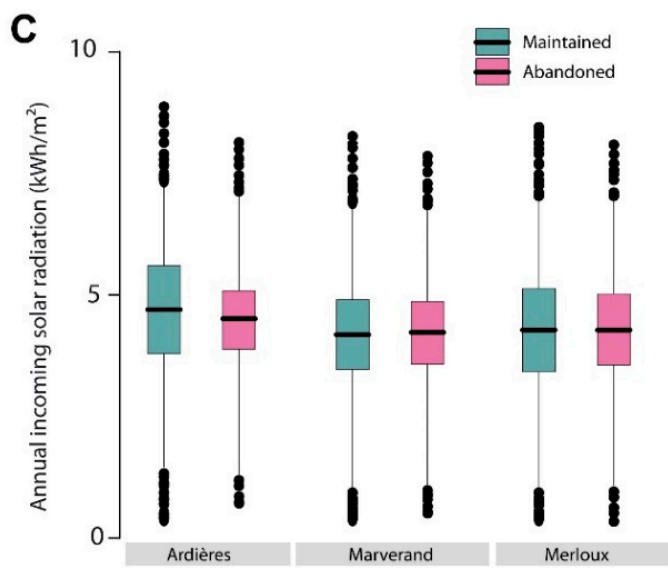

D
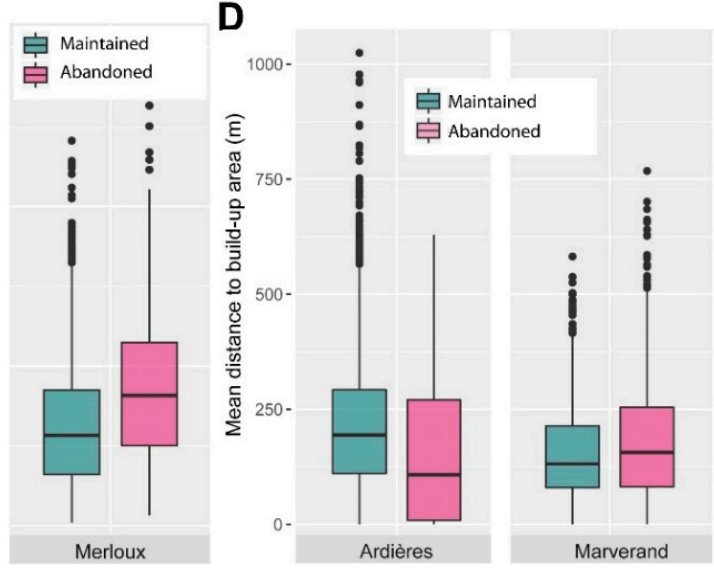

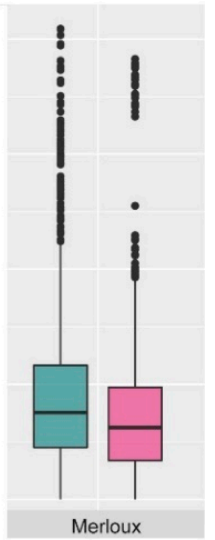

Figure 12. Local characteristics of abandoned vineyards. (A): Bar plots of the proportion of abandoned vineyards per AOC and per study area; (B): Box plots of the mean slope gradients of each study area for the abandoned and maintained vineyards; $(\mathbf{C})$ : Box plots of the potential incoming solar radiation of each study area for the abandoned and maintained vineyards; (D): Box plots of mean distance to build-up areas for the abandoned and maintained vineyards. 
Table 1. Results of the logistic regression. ISR corresponds to potential incoming solar radiation, CI corresponds to confidence intervals, $p$-values in bold correspond to results demonstrating that the statistical association is significant, AOC corresponds to Appellation d'Origine Contrôlée.

\begin{tabular}{|c|c|c|c|c|c|c|c|c|c|c|c|c|}
\hline \multirow{2}{*}{ Predictors } & \multicolumn{4}{|c|}{ Lower Ardières } & \multicolumn{4}{|c|}{ Marverand } & \multicolumn{4}{|c|}{ Merloux } \\
\hline & Odds Ratios & $C I$ & $z$-Value & $p$-Value & Odds Ratios & $C I$ & $z$-Value & $p$-Value & Odds Ratios & $C I$ & $z$-Value & $p$-Value \\
\hline $\begin{array}{c}\text { (Intercept) } \\
\text { AOC }\end{array}$ & 4.21 & $2.62-6.92$ & 5.805 & $<0.001$ & 1 & $0.80-1.26$ & 0.04 & 0.968 & 0.26 & $0.20-0.33$ & -10.48 & $<0.001$ \\
\hline Beaujolais & Ref & & & & Ref & & & & & & & \\
\hline Beaujolais-village & 0.18 & $0.11-0.31$ & -6.182 & $<0.001$ & 0.5 & $0.42-0.59$ & -8.08 & $<0.001$ & & & & \\
\hline Cru-du-Beaujolais & 0.06 & $0.04-0.10$ & -11.01 & $<0.001$ & & & & & & & & \\
\hline ISR & 0.94 & $0.87-1.01$ & -0.165 & 0.104 & 1.01 & $0.98-1.04$ & 0.106 & 0.096 & 0.97 & $0.90-1.04$ & -0.091 & 0.109 \\
\hline Slope & 1.09 & $1.04-1.14$ & 3.593 & $<0.001$ & 1.09 & $1.06-1.11$ & 7.416 & $<0.001$ & 1.14 & $1.12-1.16$ & 13.869 & $<0.001$ \\
\hline Built areas & 1 & $1.00-1.00$ & -5.235 & $<0.001$ & 1 & $1.00-1.00$ & 3.292 & 0.001 & 1 & $1.00-1.00$ & -3.671 & $<0.001$ \\
\hline
\end{tabular}




\section{Discussion}

\subsection{Social Factors Behind Vineyard Abandonment}

The regional setting exhibited a general trend of suburbanization from the Lyon metropolitan area since 1990. Suburbanization patterns appeared both in the Saône plain (urban sprawl) and green Beaujolais (market gardening) but impacted Beaujolais vineyards to a lesser extent. Concomitantly, a revitalization of farmers was observed by stakeholders as a result of market gardening, so that the rate of farms without known successors was the lowest in green Beaujolais $(20 \%-30 \%)$ and in the Saône plain areas $(30 \%-40 \%)$. Indeed, more than $25 \%$ of farmers were 40 years old or younger in green Beaujolais and in the Saône plain. In contrast, this rate was approximately $15 \%$ to $20 \%$ in the lower Ardières and lower than $15 \%$ in the Marverand and Merloux areas. Revitalization may have been hampered in the latter areas by the inertia of the vineyard system, which is often considered cultural heritage that should be maintained [33,34]. As a consequence, $50 \%$ to $70 \%$ of farms currently lack known successors in the southern vineyard area (Marverand and Merloux). Even in the northern vineyard area (AOC Cru-du-Beaujolais), 35\% to 45\% of farms currently lack known successors [14], a rate that remains significantly higher than in the green Beaujolais and the Saône plain. This gradual aging of farmers without significant renewal, therefore, creates a favorable context for the abandonment of vines.

\subsection{Vineyard Abandonment: A Return to the Natural Environment?}

The general patterns of vineyard abandonment in Beaujolais are partly similar to those observed in areas where crises in the tradition of wine growing occurred. The rate of abandonment (up to $30 \%$ in two decades) is actually quite similar to the rates assessed in southern Spain [34], southern France [8,35], and Eastern Europe [36]. Vineyards were furthermore maintained in plots considered ideal for wine (high-added-value terroirs such as AOC Cru-du-Beaujolais or to a lesser extent AOC Beaujolais-village), as typically observed [31]. This general result was nevertheless coupled with complex processes at a local scale, so that spatial patterns of vineyard abandonment were differentiated in each case study. Indeed, lower Ardières exhibited a resilient pattern; abandonment was located primarily in regular terroirs (AOC Beaujolais) while other terroirs remained mostly preserved. In the Marverand area, the general spatial pattern was coupled with a pattern that is typical of agricultural areas threatened by an economic crisis [31]: remote and steep areas were abandoned because they are labor-intensive. In the Merloux area, the spatial pattern of abandonment directly revealed the influence of suburbanization. Abandoned parcels were indeed primarily located close to built-up areas. This result can be explained by the proximity of the Lyon Metropolitan area, but also by the lack of high-quality terroirs. As the price per hectare of wine plots was very low, parcels may have appeared appropriate for other agricultural activities (e.g., market gardening) but may also be perceived as buildable areas.

Nevertheless, while many parcels would have been returned to the natural environment because of extensive vineyard abandonment [8], the spontaneous development of vegetation was quite low in Beaujolais. Typically, the first stages of spontaneous vegetation regrowth (shrub encroachment, development of a discontinuous tree layer) are observed a few years $(<10$ years) after land abandonment [37,38]. Many authors [39,40] have indeed pointed out that tree vegetation recovery may occur over 20 years. As a consequence, the growing cycles of vegetation seemed to be disturbed in Beaujolais. In detail, some old abandoned parcels ( $>15$ years old) were identified in the fields (ages were estimated by wine growers and with aerial photographs) and were characterized by a lack of shrubs and trees, although they would be expected to have reached a further stage of development $[38,41]$. Stakeholders suggested that light anthropogenic maintenance of abandoned areas occurred in which shrubs and trees were sometimes cut to prevent landscape closure. Of course, this maintenance occurred locally without any general spatial trend, as it depends on the decision of 
the farmer and on their financial resources. Landscape closure is an important environmental issue that is well considered by stakeholders, so farmers and mayors are aware of it.

Such awareness may also explain why the transformation of vines into grassland was the most frequent transition pattern in vineyard abandonment, which is a result that was not necessarily expected. Financial aid from the European Union certainly encouraged vineyard removal during the 2000s. This financial aid was paid only if the farmer maintained continuous herbaceous vegetation cover to avoid shrub encroachment and landscape closure. In addition, the price of the vineyard crops dropped significantly in the early 2000s; the owners would have had to sell them at an insufficient price to make their initial investment profitable. Conversion to grassland allows them to wait for prices to rise again.

Moreover, it was observed that these recently created grasslands were not systematically associated with agricultural activity (e.g., breeding). This trend was more intense in Marverand and Merloux. According to the stakeholder interviews, this transformation corresponded to landscape maintenance, which is a temporary stage before the parcels are sold. While urban sprawl is regulated by urban planning plans, parcel owners hope they will be able to sell parcels to real estate developers. Buildable parcels fetch much higher prices than agricultural plots, especially if they are well maintained as grasslands instead of as fallow lands.

\section{Conclusions}

All of Beaujolais is affected by suburbanization processes from the Lyon metropolitan area. However, while a significant rejuvenation of farmers occurred in both green Beaujolais and the Saône plain, aging vine growers generated a context that promotes vineyard abandonment. Vineyard surface extent has indeed decreased since the beginning of the 21st century in Beaujolais, but the spatial patterns were significantly different in the northern part of the vineyards compared to in the southern part. Approximately one-third of the surface area has disappeared southward in the Marverand and Merloux areas $(-30 \%$ and $-29 \%$, respectively), while the decrease has been significantly lower to the north in the lower Ardières area ( $-5 \%)$. Such heterogeneity revealed the locations of terroirs of better quality. Furthermore, the drivers behind the abandonment of vineyards differed among the areas. In northern Beaujolais, the winegrowers tended to abandon vine parcels that were considered of lower quality, while in southern Beaujolais, the winegrowers tended to abandon vine parcels in relation to the difficulty of maintenance (remote and steep parcels were preferentially abandoned) or in relation to the opportunity to convert the plot into building land.

While vineyard abandonment is typically associated with a return to the natural environment, we showed that most of the abandoned parcels were converted into grassland (34\% to $43 \%$ of all the changes we identified in the three studied areas). These results showed that the landscape was maintained for both environmental and economic reasons. Many owners believe that a clean parcel will be more easily sold to create new built-up areas or to develop new agricultural activity. We highlighted that the conversion into grasslands may be a temporary stage within a complex transition between vineyard abandonment and the emergence of another activity. Many stakeholders are thus eager to create new built areas or to develop new agricultural activity. The latter point can be a great opportunity to contribute to the current debate on local agriculture to provide agrifood products that would aid the conversion of grassland and abandoned parcels to promote sustainable development.

Author Contributions: Conceptualization, E.C.; methodology, E.C., J.P. and Y.L.G..; software, E.C., J.P. and M.F.; validation, M.F.; investigation, E.C., J.P. and Y.L.G.; writing-original draft preparation, E.C.; writing-review and editing, J.P., Y.L.G. and M.F.; supervision, E.C.; project administration, E.C. All authors have read and agreed to the published version of the manuscript.

Funding: This research was funded by Lyon 3 University (Programme Bourgeon "ADAGE") and Syndicat Mixte du Beaujolais.

Acknowledgments: We acknowledge with thanks B. Girard (Syndicat Mixte du Beaujolais) for administrative and technical support, and all stakeholders who asked to our questions. 
Conflicts of Interest: The authors declare no conflict of interest. The funders had no role in the design of the study; in the collection, analyses, or interpretation of data; in the writing of the manuscript, or in the decision to publish the results.

\section{References}

1. Verburg, P.H.; Crossman, N.; Ellis, E.C.; Heinimann, A.; Hostert, P.; Mertz, O.; Nagendra, H.; Sikor, T.; Erb, K.H.; Golubiewski, N. Land System Science and Sustainable Development of the Earth System: A Global Land Project Perspective. Anthropocene 2015, 12, 29-41. [CrossRef]

2. Magliocca, N.R.; Rudel, T.K.; Verburg, P.H.; McConnell, W.J.; Mertz, O.; Gerstner, K.; Heinimann, A.; Ellis, E.C. Synthesis in land change science: Methodological patterns, challenges, and guidelines. Reg. Environ. Chang. 2015, 15, 211-226. [CrossRef] [PubMed]

3. Van Vliet, J.; De Groot, H.L.F.; Rietveld, P.; Verburg, P.H. Manifestations and Underlying Drivers of Agricultural Land Use Change in Europe. Landsc. Urban Plan. 2015, 133, 24-36. [CrossRef]

4. Fernández-Nogueira, D.; Corbelle-Rico, E. Land Use Changes in Iberian Peninsula 1990-2012. Land 2018, 7 , 99. [CrossRef]

5. Lasanta, T.; Arnáez, J.; Pascual, N.; Ruiz-Flaño, P.; Errea, M.P.; Lana-Renault, N. Space-Time Process and Drivers of Land Abandonment in Europe. Catena 2017, 149, 810-823. [CrossRef]

6. Corbelle-Rico, E.; Crecente-Maseda, R.; Santé-Riveira, I. Multi-scale assessment and spatial modelling of agricultural land abandonment in a European peripheral region: Galicia (Spain), 1956-2004. Land Use Policy 2012, 29, 493-501. [CrossRef]

7. Legouy, F. La Géohistoire de L'espace Viticole Français sur Deux Siècles (1808-2010): Plusieurs Cycles Viticoles Décryptés. Espaces Temps 2014, 1-14. Available online: https://www.espacestemps.net/articles/lageohistoire-de-lespace-viticole-francais (accessed on 12 April 2020).

8. Vinatier, F; Arnaiz, A.-G. Using high-resolution multitemporal imagery to highlight severe land management changes in Mediterranean vineyards. Appl. Geogr. 2018, 90, 115-122. [CrossRef]

9. Lammoglia, A.; Leturcq, S.; Delay, E. Le modèle VitiTerroir pour simuler la dynamique spatiale des vignobles sur le temps long (1836-2014). Cybergeo Eur. J. Geogr. 2018, 863. [CrossRef]

10. Robinson, G.M. Globalization of agriculture. Annu. Rev. Resour. Econ. 2018, 10. [CrossRef]

11. Robinson, G.M. New Frontiers in agricultural geography: Transformations, food security, land grabs and climate change. Boletín Asoc. Geógrafos Españoles 2018, 78, 1-48. [CrossRef]

12. Arnal, C.; Laurens, L.; Soulard, C. Les mutations paysagères engendrées par l'arrachage viticole, un vecteur de mobilisation des acteurs territoriaux dans l'Hérault. Méditerranée 2013, 120, 49-58. [CrossRef]

13. AGRESTE. Valorisation des Surfaces de Vignes Arrachées en Beaujolais. Retours D'expériences D'agriculteurs Pour une Utilisation en Cultures Fourragères ou Céréalières; Service statistique et prospective, Ministère de L'agriculture et de L'alimentation: Paris, France, 2018; pp. 1-46.

14. AGRESTE. Valeurs Vénales des Terres; Service Statistique et Prospective, Ministère de L'agriculture et de L'alimentation: Paris, France, 2018; pp. 1-56.

15. Almstedt, Å.; Brouder, P.; Karlsson, S.; Lundmark, L. Beyond post-productivism: From rural policy discourse to rural diversity. Eur. Countrys. 2014, 6, 297-306. [CrossRef]

16. Wilson, G.A. The spatiality of multifunctional agriculture: A human geography perspective. Geoforum 2009, 40, 269-280. [CrossRef]

17. Wilson, G.A. From 'weak' to 'strong' multifunctionality: Conceptualising farm-level multifunctional transitional pathways. J. Rural Stud. 2008, 24, 367-383. [CrossRef]

18. Météo-France. Available online: http://www.meteofrance.com/climat/france/lyon/69029001/normales (accessed on 12 April 2020).

19. Anselme, B.; Bousquet, F.; Lyet, A.; Etienne, M.; Fady, B.; Le Page, C. Modelling of spatial dynamics and biodiversity conservation on Lure mountain (France). Environ. Model. Softw. 2009, 25, 1385-1398. [CrossRef]

20. Anderson, B.; McFarlane, J. Assemblage and geography. Area 2011, 43, 124-127. [CrossRef]

21. R Development Core Team. R: A Language and Environment for Statistical Computing; R Foundation for Statistical Computing: Vienna, Austria, 2005; ISBN 3-900051-07-0.

22. Shao, G.; Wu, J. On the accuracy of landscape pattern analysis using remote sensing data. Landsc. Ecol. 2008, 23, 505-511. [CrossRef] 
23. Hermosilla, T.; Díaz-Manso, J.M.; Ruiz, L.A.; Recio, J.A.; Fernández-Sarría, A.; Ferradáns-Nogueira, P. Analysis of parcel-based image classification methods for monitoring the activities of the Land Bank of Galicia (Spain). Appl. Geomat. 2012, 4, 245-255. [CrossRef]

24. Houet, T.; Loveland, T.R.; Hubert-Moy, L.; Gaucherel, C.; Napton, D.; Barnes, C.A.; Sayler, K. Exploring subtle land use and land cover changes: A framework for future landscape studies. Landsc. Ecol. 2010, 25, 249-266. [CrossRef]

25. Attri, P.; Chaudhry, S.; Sharma, S. Remote Sensing \& GIS based Approaches for LULC Change Detection- A Review. Int. J. Curr. Eng. Technol. 2015, 5, 3126-3137.

26. Stefanakis, E. Modelling the history of semi-structured geographical entities. Int. J. Geogr. Inf. Sci. 2003, 17, 517-546. [CrossRef]

27. Marie, M. Des Pratiques des Agriculteurs à la Production de Paysage de Bocage. Étude Comparée des Dynamiques et des Logiques D'organisation Spatiale des Systèmes Agricoles Laitiers en Europe (Basse-Normandie, Galice, Sud de l'Angleterre). Ph.D. Thesis, Université de Caen, Caen, France, 2009.

28. Batty, M. Network Geography: Relations, Interactions, Scaling and Spatial Processes in GIS; UCL Working Papers Series 63; Centre for Advanced Spatial Analysis: London, UK, 2003.

29. Spéry, L.; Claramunt, C.; Libourel, T. A spatio-temporal model for the manipulation of lineage metadata. Geoinformatica 2001, 5, 51-70. [CrossRef]

30. Poinsot, Y. Le rôle des formes spatiales dans l'enfrichement des moyennes montagnes audoises: Esquisse d'une géographie du voisinage. Espace Géographique 1997, 26, 247-260. [CrossRef]

31. Sluiter, R.; De Jong, S.M. Spatial patterns of Mediterranean land abandonment and related land cover transitions. Landsc. Ecol. 2007, 22, 559-576. [CrossRef]

32. McLafferty, S. Spatial context. In The International Encyclopedia of Geography; Richardson, D., Castree, N., Goodchild, M., Kobayashi, A., Liu, W., Marston, R.A., Eds.; John Wiley \& Sons Ltd.: Hoboken, NJ, USA, 2017. [CrossRef]

33. McFarlane, J.; Grant, B.; Blackwell, B.; Mounter, S. Combining amenity with experience: Exploring the hidden capital of a winescape experience. Tour. Econ. 2017, 23, 1076-1095. [CrossRef]

34. Foronda-Robles, $\mathrm{C}$. The territorial redefinition of the Vineyard Landscape in the sherry wine region (Spain). Misc. Geogr. 2018, 22, 95-101. [CrossRef]

35. Cheylan, J.-P. Evolution de l'occupation des sols en hautes garrigues viticoles et périurbaines de l'Hérault. In Dynamique Rurale, Environnement et Stratégies Spatiales. In Proceedings of the Colloque International CNRS, Montpellier, France, 13-14 September 2001; Université Montpellier III: Montpellier, France, 2001.

36. Lieskovský, J.; Kanka, R.; Bezák, P.; Štefunková, D.; Petrovič, F.; Dobrovodská, M. Driving forces behind vineyard abandonment in Slovakia following the move to a market-oriented economy. Land Use Policy 2013, 32, 356-365. [CrossRef]

37. Génot, J.-C.; Schnitzler, A. La France des Friches-De la Ruralité à la Féralité; Quae: Paris, France, 2012.

38. Houzard, G.; Lecointe, A. A biogeographical study of waste lands: Preliminary results. Rev. Géographie Lyon 1991, 66, 38-46. [CrossRef]

39. Debussche, M.; Escarre, J.; Lepart, J.; Houssard, C.; Lavorel, S. Changes in mediterranean plant succession: Old-fields revisited. J. Veg. Sci. 1996, 7, 519-526. [CrossRef]

40. Bonet, A. Secondary succession of semi-arid Mediterranean old-fields in south-eastern spain: Insights for conservation and restoration of degraded lands. J. Arid. Environ. 2004, 56, 213-233. [CrossRef]

41. Balooni, K.; Singh, K. Prospects and problems of afforestation of wastelands in India: A synthesis of macroand micro-perspectives. Geoforum 2007, 38, 1276-1289. [CrossRef]

(C) 2020 by the authors. Licensee MDPI, Basel, Switzerland. This article is an open access article distributed under the terms and conditions of the Creative Commons Attribution (CC BY) license (http://creativecommons.org/licenses/by/4.0/). 